JGG 2021;69:19-25

doi: 10.36150/2499-6564-447

\title{
Polypharmacy and the senior citizen: the influence of direct-to-consumer advertising
}

Linda Sperling, DHA, MSN, RN¹, Martine B. Fairbanks, Ed.D, MA, BS ${ }^{2}$

${ }^{1}$ College of nursing, University of Phoenix, Arizona, USA; ${ }^{2}$ College of doctoral studies, University of Phoenix, Arizona, USA

Background. Polypharmacy, or taking five or more medications daily, can lead to poor medication compliance and an increased risk for adverse drug-to-drug interactions that may eventually lead to death. The study was designed to explore the questions of how age, the relationship between the physician and patient, and television, radio, magazines and modern electronic technology, such as the Internet, affect patients' understanding of their medical care. Two main areas addressed in this research study included the pharmaceutical industry's influence on consumer decisions to ask a physician for a particular medication, and the prescribing practices of the physician.

Methods. This qualitative phenomenological study began with prescreening volunteer residents in a nursing home to discover potential participants who met the criteria of using five or more medicines daily. We then interviewed 24 participants who met the criteria, using semi-structured interview questions.

Results. Four core themes emerged from this study: professional trust, professional knowledge, communication deficit, and direct-to-consumer advertising. Participants reported trusting their doctors and taking medications without question, but most knew why they were taking the medications. Participants also reported seeing ads for medications, but only one reported asking a physician to prescribe the medication.

Conclusions. The findings from this research study showed that consumers may be becoming wiser with modern technology at their fingertips. The consumers appear to be searching for a higher level of ownership regarding their health care and seeking more of a partnership-type of relationship with their physicians.

Key words: polypharmacy, direct-to-consumer advertising, medications, prescription, non-prescription, prescription prescribing practices, elderly, senior citizen

rbanks MB. Polypharmacy and the senior citizen: the influence of direct-to-consumer advertising. Journal of Gerontology and Geriatrics 2021;69:19-25. https:// doi.org/10.36150/2499-6564-447

(c) Copyright by Società Italiana di Gerontologia e Geriatria (SIGG)

\section{(c) (1) (2) $\odot$}

\section{OPEN ACCESS}

This is an open access article distributed in accordance with the CC-BY-NC-ND (Creative Commons Attribution-NonCommercial-NoDerivatives 4.0 International) license. The article can be used by giving appropriate credit and mentioning the license, but only for non-commercial purposes and only in the original version. For further information: https://creativecommons.org/licenses/by-nc-nd/4.0/deed.en

\section{INTRODUCTION}

Medication is possibly the most important health care technology available for the prevention of disease, illness, disability, and death for the 65-and-older age population ${ }^{1}$. At the same time, it is just as important to make sure the medications a patient takes are not part of the problem that can lead to disability, a decreased quality of life ${ }^{2}$ or death. Polypharmacy is associated with adverse drug reactions, geriatric syndromes, such as urinary incontinence, poor medication adherence and the inappropriate prescribing where the risk may outweigh the benefit when there are safer alternatives available ${ }^{3}$. 
When a medication is either immoderate or unwarranted, it has the potential to be dangerous due to the risk for complications. This risk increases with each new medication a patient adds to their daily medication regimen. Understanding the problem of polypharmacy among geriatricians, internists, and generalists as well as the non-physician that includes the pharmacist, nurse, policymaker is essential ${ }^{4}$. This article addresses the influence direct-to-consumer advertising and the prescribing practices of the physician have on the senior citizen and polypharmacy.

As patients age, the individual progressively develops more health problems. This is known as co-morbidity and the presence of one or more diseases may lead to polypharmacy ${ }^{5}$ which adds to the risk of an adverse drug reaction occurring ${ }^{6}$.

It has become evident to most health care professionals that inappropriate medication use as well as polypharmacy are associated with the negative clinical outcomes that include cognitive and functional impairments, delirium, malnutrition and weight loss as well as show an increase in patient falls causing hip fractures hospitalizations and a potential nursing home placement, incontinence, and a decrease in quality of life ${ }^{4}$. The senior citizen with many complex medical problems often is prescribed multiple medications and treatments ${ }^{7}$. On average, individuals over 65 take two to five prescription medications daily ${ }^{8}$. The older population of Americans takes approximately 34\% of prescription drugs, and as much as 40" of over-the-counter medications ${ }^{9}$. According to Rochon ${ }^{10}$, the most frequent medical intervention a physician performs is writing a prescription. Many patients become a victim of what is known as the prescribing cascade, which begins when a patient has an adverse reaction to a drug. This reaction may be misdiagnosed as a new medical condition for which a new drug is prescribed ${ }^{10}$. This prescribing cascade has the potential to place the patient at risk for further side effects to occur. The over 65 age group, who tend to be given a large number of prescription medications, are at a much higher risk for receiving medications that may be inappropriate for them. An inappropriate medication is described as one in which the risk outweighs the benefit. These risk/benefit ratios may be affected by age-related changes in medications, pharmacokinetics, and pharmacodynamics in the over 65 population ${ }^{11}$.

In order to make improvements in prescribing practices, changes in policies within institutions, improvements in marketing strategies, and, most important, providing better guidelines in the practitioner's clinical practice must occur ${ }^{12}$. In 1985, advertising of pharmaceuticals became legal in the United States. Leaders of pharmaceutical companies began expanding their advertising into magazines and newspapers. Officials of the FDA ruled that these forms of advertising must adhere to the same standards as those aimed at the providers ${ }^{13}$. In 2010 important changes were made by the Federal Drug Administration (FDA) that mandated that advertisers must provide truthfulness and represent a fair balance between the benefits and risks associated with an advertisement. Other improvements to the direct-toconsumer guidelines include the provision of a clearly written, conspicuous, and neutral statement of the side effects and contraindications of a medication.

Proponents of direct-to-consumer advertising claim it is very influential in getting the consumer to request a specific medication from their primary caregiver. Mangin and Toop ${ }^{13}$ state direct-to-consumer advertising is used "to drive choice rather than to inform it" (p. 1). Bonaccorso and Sturchio ${ }^{14}$ argue that direct-to-consumer advertising enables patients to make a better, more informed choice about the type of treatment they expect to receive.

On the other hand, Mintzes ${ }^{15}$ believes that direct-toconsumer advertising might be responsible for medicalizing. Medicalization is described as a process in which non-medical problems are defined and treated as medical problems ${ }^{16}$. The term medicalization describes how a common emotion or trait can be turned into a treatable condition ${ }^{17}$. For example, bad breath is called halitosis and symptoms associated with menses are referred to as premenstrual syndrome (PMS). Societal forces that help to form the trend of medicalization are that costs are reimbursable from an insurance company if they can be linked to a definable medical condition, and research funding is generally given for problems that define a disease. Another example of medicalizing is obesity. Obesity is considered a disease that places the blame on the result rather than the person's lifestyle and actions ${ }^{17}$.

The Elaboration Likelihood Model, part of the cognitive response model, was used as a conceptual construct for the study. This model postulates that the listener will think about the meaning of the message which will induce thinking, thereby creating a motivation for the consumer to decide if this medication is right for them, then uses persuasion to inspire the consumer to ask their physician for the medication. Individuals diagnosed with a serious health condition, such as heart disease, would be more likely to conduct a more extensive search for and process health-related information than an individual who enjoys good health. Thus, those individuals diagnosed with a serious health condition, such as heart disease, would be more likely to conduct a more extensive search for and process health-related information than an individual who enjoys good health ${ }^{18}$. 
The Social Identity Theory uses similarities among various groups of people, such as age, to influence attitudes or judgements ${ }^{19}$. Identity-relevant information is useful when an individual's social identity factors are activated. Identity salience, which is a heightened sensitivity for the consumers to respond to a stimuli, may influence the consumers to purchase a product ${ }^{19}$ or, in this case, to ask their physicians for a specific medication.

The Culmination Theory expects the consumer to request a medication from their physician after repeatedly viewing a pharmaceutical advertisement. Such a scenario is particularly true when the advertiser uses an actor to portray a patient claiming to be free of disease symptoms as a result of the advertised drug ${ }^{20}$. After repeatedly viewing this type of advertisement, the viewers will begin to believe that the advertised medication would work for them.

The research study was conducted to discover how individuals, age 65 and over, residents of a retirement center, and living in the state of California, perceive the role of direct-to-consumer advertising in influencing their decisions to ask a physician for a specific medication. The investigation collected data on the inter-relation among the media, the elderly, and the potential for polypharmacy. The purpose of collecting and reporting these data was to answer three main research questions. Question number 1 asked how individuals, age 65 and over, residents of a retirement center, and living in the state of California, perceive the role of directto-consumer advertising in influencing their decisions to ask a physician for a specific medication. Question number 2 asked about the individuals' experiences about the communication process when requesting an advertised medication from a physician. Question number 3 asked how knowledgeable individuals are about the prescription and over-the-counter medications they take.

The purpose of this phenomenological study was to examine how direct-to-consumer advertising and the physician influence polypharmacy and to explore the experiences of individuals, age 65 and older, taking five or more prescription or over the counter medications daily.

\section{METHODS}

\section{DESIGN}

This qualitative study was designed and conducted, using a phenomenological approach, to explore the experiences of active senior citizens who live in a retirement center in California, are age 65 and older, and take five or more prescription medications daily. This study addressed the pros and cons of direct-to-consumer advertising as well as the influence it had on the elderly population. The major data source used to gain the inner perspective was through the interview process ${ }^{21}$.

The assumption with phenomenology is that with every shared experience there is meaning ${ }^{22}$. To understand the lived experiences of senior citizens related to polypharmacy and the influence direct-to-consumer have on the senior citizen, participants living in a retirement center were selected intentionally. In this case, the participants' lived experiences relate to their medications and perspectives on direct-to-consumer advertising. The goal of this research study was to identify factors related to patients' understanding about the medications they are taking and what led to the individuals obtaining prescriptions for the medications. This study's ultimate aim was to help the consumer make a more informed decision about the medications they choose to take and to encourage the nurse to be proactive in advocating for public education as a way to improve the quality and effectiveness of health care.

\section{PARTICIPANTS}

The researchers invited individuals, age 65 or over, living in a nursing home in the state of California, taking five or more medications daily as the criteria to participate in the study. The study used the purposive sampling method to obtain the number of participants needed who fit the qualifying criteria. The participants were selected based on qualifying questions, including age, number of prescription medication and over the counter medications taken daily, not requiring assistance with their medications, and their cognitive ability to answer questions knowledgeably. Of the original 31 who volunteered, seven did not fit the criteria, and the other 24 were included in the interviews for the study. The mean age of the participants was 86 .

The interviews addressed the role that direct-toconsumer advertising had in their decision to ask their physician for a specific medication. We identified any similarities in the participants' lack of knowledge related to the use of specific medications in the elderly population. We identified the false assumptions that consumers have about the safety of direct-to-consumer advertising. Patients' beliefs and attitudes about medications may also be influenced by the doctor-patient relationship. Patient trust may facilitate a willingness to tolerate polypharmacy in a context of uncertainty, but it may equally influence patients' willingness to deprescribe ${ }^{3}$. A limitation to this study was that all the participants surveyed are members of the same senior citizen community. Some participants were either nurses, spouses and family of medical professionals which may or may not have played a role on their knowledge of direct-toconsumer advertising. 


\section{DATA COLLECTION}

IRB approval was sought and granted before data collection began. A total of 31 participants were interviewed. Twenty four participants were included in this study as seven participants were disqualified during the interview process when it was discovered they did not meet the qualifying criteria for the study. Typically, the focus of qualitative research is only on a few individuals, or a subset of a population. The study was conducted in English, audio-taped with signed consent and transcribed verbatim. The study was completed when data saturation was confirmed.

This research study used a subjective approach through the use of open-ended, survey-type interview questions. A field test was conducted for comprehensibility and the possibility of producing additional questions. This field test used two volunteers who met the criteria of the participant population but were not included as participants in the actual study. Phenomenological reduction was used through continuous reflection on the experiences presented by the study participants as a way to facilitate the development of themes ${ }^{23}$. Bracketing was used to preserve the focus on the research that required the identification of any personal experiences; cultural factors, assumptions, and hunches that may influence the way the data are viewed ${ }^{24}$. Horizontalizing was used to provide equal weight to each response ${ }^{25}$. Clustering of the themes was used to combine the experience of the participant ${ }^{24}$.

\section{RESULTS}

The specific problem addressed in this study was the role direct-to-consumer advertising and the physician played in influencing the unhealthy pattern of overuse and misuse of medications by the senior citizen, resulting in polypharmacy.

The study participants all live in the same retirement community. They were selected using a purposive sampling method; all volunteers were prescreened to make sure they met the criteria. In order to take part in the study, potential participants were asked the following three questions during the participant selection process: What is your age? How many different prescription medications do you take every day? What type of assistance do you need taking your medications? To qualify for the study, participants had to be age 65 and over, take five or more medications daily, either prescription or over the counter, and be able to take the medications unassisted.

All study participants willingly shared their lived experiences with direct-to-consumer advertising of pharmaceutical products and physician prescribing practices.
All of the participants acknowledged having seen or heard the advertisements on the television or radio or having read them in a magazine or newspaper. All of the participants admitted to hearing or seeing one or more forms of direct-to-consumer advertising.

The first question asked how individuals, age 65 and over, perceive the role of direct-to-consumer advertising in influencing their decision to ask a physician for a specific medication.

The participants stated that they either turned down or turned off the television or radio or ignored them completely. One participant, when asked to expand upon their answer, added they believed that direct-toconsumer advertising was a way for the pharmaceutical company to sell their product and profit from it. Another participant stated, this type of advertising resulted in people taking medications they did not need to take.

According to the participants' responses, the influence of direct-to-consumer advertising appeared as one of the top four themes in three of the eight interview questions. When the respondents were asked the question about their thoughts on drug or pharmaceutical advertising on the TV, radio, or in a magazine, eighteen (75\%) of the participants responded to the question by saying they saw it, but either did not pay attention to it or it did not interest them. Seven (29\%) responded yes, but only one $(0.04 \%)$ admitted asking the doctor for the medication.

What are individuals' experiences about the communication process when requesting an advertised medication from their physician, and the side effects, purpose of, and things to look out for when the physician provided a prescription to the participant? Sixteen (66.6\%) of all respondents have complete trust in their physicians stating they take their medications because their physician told them to. Six (25\%) of the respondents were unable to explain the purpose of at least two of the medications that they took. All the participants agreed that they get their information primarily from the papers that come with the medications or read the label on the bottle.

Fourteen (58.3\%) stated they either believe what the doctor tells them or they just take them because the doctor told them to take them. Twelve (14\%) report hearing about medications on the TV and using a PDR, Medline, or the Internet to learn about how a medication works.

Four themes emerged from the study. The four themes included a) professional trust, b) professional knowledge, c) communication deficit, and d) direct-to-consumer advertising. The first theme, professional trust showed that one hundred percent of the participants admitted to not getting an explanation about their medications when receiving the prescription. 
The theme of professional trust played a large part in the study as all but one participant stated they had complete trust in their physician's decisions to prescribe their medications for them. All the participants reported taking the medications without questioning the reasoning, side effects, contraindications, or what to look out for. One participant stated that "I only take the medicine because my doctor told me to". Another said, "I asked my doctor about one medication because I thought it might help me. But he didn't give it to me".

The second emergent theme from the study was professional knowledge. The theme professional knowledge was evident in the answers due to their educational levels, economic status, and or family connections within the medical field. Some participants believed that the reason their physician did not explain anything to them was because either they or a family member was in the medical field.

The third theme, communication deficit was evident in six of the eight interview questions. Along with the respondents' trust in their physician or the past medical knowledge of themselves or their loved ones, come the knowledge deficit that is due to a lack of communication between the physician and the patient. One participant stated, "My doctor did not give me any handouts or explain anything to me about the medication because my daughter is a nurse". Another stated "I did not get any information about the medicine because my husband was a doctor". Three participants said that they get their information from the handout that the pharmacy gives them when they fill their prescription. One stated "I get the information from the pharmacy, but I throw it out because my doctor told me I needed to take the medication".

The fourth theme, direct-to-consumer advertising found the most common response consistent among the participants was that they did not like it or very few paid any attention to it at all. Some responses were, "I'm not in favor of it. I am not in favor of advertising medication over the TV because they lead to misunderstandings by patients and adverse effects, side effects, etc. so the average patient doesn't know", and "I really don't think people should be doing it", and "I think it gives people ideas that they don't need".

One respondent said, "I saw the advertising but didn't pay attention to it". Another stated, "I don't agree with them. It is just a sales pitch, and the company wants to direct you to ask your doctor about their product". He further added, "But when you see all the side effects about a medication you won't want to take anything". One person admitted trying to get medication she saw advertised, "I asked my doctor once for a medication because I was curious about it and the advertisement told me to ask my doctor if it would be right for me".
Table I shows the participants considered and selected for the research study, demographics, including gender and age. The four themes are listed by number of participants responding to questions one through eight and the percentage of coded transcribed interviews within the emergent themes by question.

\section{DISCUSSION}

Interpretation of the results of the in-person, semistructured interviews using eight open-ended questions

Table I. Participant responses \& themes.

\begin{tabular}{|c|c|c|}
\hline Participant data \& themes & Participant = n & Percent \% \\
\hline Participants considered & 36 & \\
\hline Participants disqualified & 10 & \\
\hline Pilot study participants & 2 & \\
\hline Study participants & 24 & \\
\hline \multicolumn{3}{|l|}{ Gender } \\
\hline Male & 3 & \\
\hline Female & 21 & \\
\hline Age, mean (range) & $86(83-102)$ & \\
\hline \multicolumn{3}{|l|}{ Theme by question 1} \\
\hline Communication deficit & 6 & $27.13 \%$ \\
\hline Professional trust & 6 & $25.56 \%$ \\
\hline \multicolumn{3}{|l|}{ Theme by question 2} \\
\hline Communication deficit & 1 & $2.21 \%$ \\
\hline Professional trust & 18 & $33.81 \%$ \\
\hline \multicolumn{3}{|l|}{ Theme by question 3} \\
\hline Communication deficit & 6 & $25.94 \%$ \\
\hline Professional trust & 13 & $35.47 \%$ \\
\hline Professional knowledge & 1 & $2.69 \%$ \\
\hline \multicolumn{3}{|l|}{ Theme by question 4} \\
\hline Communication deficit & 1 & $2.21 \%$ \\
\hline Professional knowledge & 2 & $6.03 \%$ \\
\hline Influence of DTC advertising & 18 & $33.81 \%$ \\
\hline \multicolumn{3}{|l|}{ Theme by question 5} \\
\hline Communication deficit & 1 & $1.42 \%$ \\
\hline Professional trust & 2 & $14.29 \%$ \\
\hline Professional knowledge & 1 & $6.80 \%$ \\
\hline Influence of DTC advertising & 8 & $14.61 \%$ \\
\hline \multicolumn{3}{|l|}{ Theme by question 6} \\
\hline Influence of DTC advertising & 2 & $5.93 \%$ \\
\hline \multicolumn{3}{|l|}{ Theme by question 7} \\
\hline Communication deficit & 8 & $19.93 \%$ \\
\hline Professional trust & 3 & $12.76 \%$ \\
\hline Professional knowledge & 4 & $7.05 \%$ \\
\hline \multicolumn{3}{|l|}{ Theme by question 8} \\
\hline Communication deficit & 6 & $24.19 \%$ \\
\hline Professional trust & 2 & $3.96 \%$ \\
\hline Professional knowledge & 4 & $1.56 \%$ \\
\hline DTC: direct-to-consumer & & \\
\hline
\end{tabular}


Table II. Theme descriptions.

\begin{tabular}{|c|c|}
\hline Theme and pattern & Description \\
\hline Professional knowledge & $\begin{array}{l}\text { The knowledge gained from education as a physician, nurse, or family member of a } \\
\text { physician or nurse }\end{array}$ \\
\hline Professional trust & $\begin{array}{l}\text { The complete faith in the physician's professional knowledge and exercise of judgment to } \\
\text { work in the participant's best interest }\end{array}$ \\
\hline Influence of direct-to-consumer advertising & $\begin{array}{l}\text { The amount of influence the marketing of pharmaceutical products has on the public to } \\
\text { request an advertised medication from the physician }\end{array}$ \\
\hline Communication deficit & $\begin{array}{l}\text { The discussion between the physician and the patient related to drug name, use, side } \\
\text { effects, and when to call the doctor }\end{array}$ \\
\hline
\end{tabular}

focused on the research questions. The research questions were instrumental in providing the structure for the research study. The questions also provided focus and direction for the study. The interview questions also brought up the emergent core themes and patterns, which ultimately assisted in the process of describing the phenomenon as it relates to the research question.

\section{CONCLUSIONS}

Medication is possibly the most important health care technology available for the prevention of disease, illness, disability, and death for the 65-and-older age population ${ }^{1}$. At the same time, it is just as important to make sure the medications a patient takes are not part of the problem that can lead to disability, a decreased quality of life ${ }^{2}$ or death. Polypharmacy is associated with adverse drug reactions, geriatric syndromes, such as urinary incontinence, poor medication adherence and the inappropriate prescribing where the risk may outweigh the benefit when there are safer alternatives available ${ }^{3}$.

Some issues identified in this study include inadequate communication between the patient and the provider, a lack of understanding of specific instructions on taking a medication correctly and receiving an unclear discharge summary form upon release from a hospital. This study may bring awareness to the medical community of the need for preparing and mentoring nurses working in the field, as well as those just entering the profession about the importance of communicating with the patient about their medications. This study may also encourage nurses to be proactive in participating in the research process and advocating for public education as a way to improve the quality and effectiveness of health care. Raising awareness among the physician, nurse, and consumer, about the influence direct-to-consumer advertising may have on the patient may help to save lives ${ }^{26,27}$.

The pharmaceutical industry has shown significant advancements in improving the health of Americans by introducing new and better therapeutic agents, providing education to physicians, and improving patient access to medications. Improvements in medical care and in preventative measures have led to dramatic increases in life expectancy in America over the last century. Almost half of the population in the United States is expected to live past the age of $80^{28}$; the polypharmacy issue is likely to remain important.

\section{References}

1 Avorn J, Ed. Medication use and the elderly: current status and opportunities. Health Aff 1995;14:276-86. https://doi. org/10.1377/hlthaff.14.1.276

2 Feinberg JL. Introduction ensuring appropriate, effective, and safe medication use for older people. Generations 2000:24 5-7 (http://generations.metapress.com/content/ r6666115u7373318).

3 Clyne B, Cooper JA, Boland F, et al. Beliefs about prescribed medication among older patients with polypharmacy: a mixed methods study in primary care. Brit J Gen Pract 2017;67:e507-18. https://doi.org/10.3399/ bjgp17X691073

4 Garfinkel D. Poly-de-prescribing vs polypharmacy: The weapon to fight an iatrogenic epidemic: an overview. Eur J Geriatric Gerontology 2019;1:1-10. https://doi. org/10.4274/ejgg.galenos.2019.14

5 Viktil KK, Blix HS, Moger TA, et al. Polypharmacy as commonly defined is an indicator of limited value in the assessment of drug-related problems. Brit J Clin Pharmaco 2006;63:187-95. https://doi.org/10.1111/j.13652125.2006.02744.x

6 Huh J, DeLorme DE, Reid LN, et al. Direct-to-consumer prescription drug advertising. Minn Med 2010;93:50-2. PMID: 20429178

7 Fialova D, Onder G. Medication errors in elderly people: contributing factors and future perspectives. Brit $\mathrm{J}$ Clin Pharmaco 2009;67:641-5. https://doi.org/10.1111/ j.1365-2125.2009.03419.x

8 Iyer S, Naganathan V, McLachlan AJ, et al. Medication withdrawal trials in people aged 65 years and older. Drug Aging 2008;25:1021-31. https://doi.org/10.2165/00025122008251200004 
9 Garcia RM. Five ways you can reduce inappropriate prescribing in the elderly: a systematic review. J Fam Pract April 2006;55:305-12 (https://www.atrainceu.com).

10 Rochon PA, Gurwitz JH. Optimising drug treatment for elderly people: the prescribing cascade. Brit Med J 1997;3151096. https://doi.org/10.1136/bmj.315.7115.1096

11 Aparasu R, Mort J. Inappropriate prescribing for the elderly: beers criteria-based review. Ann Pharmaco 2000;34:33846. https://doi.org/10.1345/aph.19006

12 Figueiras A, Sastre I, Gestal-Otero JJ. Effectiveness of educational interventions on the improvement of drug prescription in primary care: a critical literature review. J Eval in Clin Pract 2001;7:223-41. https://doi.org/10.1046/j.13652753.2001.000234.x

13 Myers SD, Royne MB, Deitz GD. Direct-to-consumer advertising: exposure, behavior, and policy implications. J Public Policy Mark 2011;30:110-8. https://doi. org/10.1509/jppm.30.1.110

14 Mangin D, Toop L. Direct to consumer advertising in New Zealand: is the end in sight? Upfront 2006; (http://www. upfront.scholastic.com).

15 Bonaccorso SN, Sturchio JL. Direct to consumer advertising is medicalising normal human experience. Brit Med J 2002;324:910-1. https://doi.org/10.1136/ bmj.324.7342.910

16 Mintzes B. Direct to consumer advertising is medicalising normal human experience. Brit Med J 2002;324:908-11. https://doi.org/10.1136/bmj.324.7342.908

17 Kawachi I, Conrad P. Medicalization and the pharmacological treatment of blood pressure. In: Contested ground: public purpose and private interest in the regulation of prescription drugs. New York, NY: Oxford University Press 1996, pp. 26-41.

18 Bhabha $H$, Brandt A, Kass AM, et al. Medicalization: a medical humanities symposium. In: Medicalization: a medical humanities symposium, 2009, April. Symposium conducted at the Humanities Center at Harvard, Emerson Hall, Cambridge, MA.

19 Lee B, Salmon, CT, Pack HJ. The effects of information sources on consumer reactions to direct-to-consumer (DTC) prescription drug advertising: a consumer socialization approach. J Advertising Spring 2007;36:107-19. https://doi.org/10.2753/JOA009108

20 Forehand MR, Deshpande R, Reed A. Identity salience and the influence of differential activation of the social self-schema on advertising response. J App Psych 2002;87:10869. https://doi.org/10.1037/0021-9010.87.6.1086

21 Cook D. The culmination theory [Online forum comment]. 2008, November 6 (http://dannycookcrs.blogspot. com/2008/11/culmination-theory.html).

22 Patton MQ. Qualitative research and evaluation methods (2 $2^{\text {nd }}$ Ed.). Newbury Park, CA: Sage 1990.

23 Law M, Stewart D, Letts L, et al. Guidelines for critical review of qualitative studies, 1998 (http://www.usc.edu).

24 Von Manen M. The phenomenological reduction: concreteness 2011 (http://www.phenomenologyonline.com).

25 Moustakas C. Phenomenological research methods. Thousand Oaks, CA: Sage 1994.

26 Merriam SB. Qualitative research: a guide to design and implementation. San Francisco, Jossey-Bass 2009 (http:// www.mispp.edu).

27 Gellad ZF, Lyles KW. Direct-to-consumer advertising of pharmaceuticals. Am J Med 2007;120:475-80. https:// doi.org/10.1016/j.amjmed.2006.09.030

28 Heuberger RA, Caudell, K. Polypharmacy and nutritional status in older adults. Drugs Aging 2011;28:315-23. http:// dx.doi.org/10.2165/11587670 